\title{
QUALIDADE DE DADOS FLUVIOMÉTRICOS OBTIDOS ATRAVÉS DE PERFILAMENTO ACÚSTICO ${ }^{1}$
}

\author{
Mateus Ricardo Nogueira Vilanova² e José Antônio Perrella Balestieri
}

\begin{abstract}
RESUMO - Perfiladores acústicos Doppler de corrente são, na atualidade, a principal opção para medição de vazão e monitoramento hidrodinâmico de cursos d'água, em substituição aos métodos tradicionais. A disseminação desse tipo de equipamento deve-se, principalmente, às suas vantagens operativas, que vão da rapidez de medição até o maior detalhamento e quantidade de informações geradas sobre a hidrodinâmica das seções hidrométricas. Assim como no emprego de métodos e equipamentos tradicionais, o uso de perfiladores acústicos Doppler deve ser pautado pela busca da qualidade dos dados, uma vez que estes são a base para projetos e gestão de obras e sistemas de recursos hídricos. Nesse sentido, o trabalho apresenta uma análise das incertezas de medição de uma campanha hidrométrica realizada no Rio Sapucaí (Piranguinho-MG), utilizando dois perfiladores Doppler distintos: um ADCP Rio Grande 1.200 kHz e um Qmetrix Qliner. Foram realizadas 10 medições consecutivas com cada equipamento, seguindo-se os protocolos de qualidade existentes na literatura e, posteriormente, uma análise de incerteza do Tipo A (ou seja, análise estatística de várias observações independentes das grandezas de entrada sob as mesmas condições). As medições do ADCPe Qliner apresentaram, respectivamente, incertezaspadrão de $0,679 \%$ e $0,508 \%$ em relação às médias. Tais resultados são satisfatórios e aceitáveis quando comparados a referências da literatura, indicando a validade do uso de perfiladores Doppler para a expansão de redes fluviométricas e geração de dados hidrológicos.
\end{abstract}

Palavras-chave: Medição de vazão fluvial; Perfiladores acústicos Doppler de corrente; Análise de incerteza.

\section{QUALITY ANALYSIS OF STREAMFLOW DATA OBTAINED BY ACOUSTIC PROFILING}

\begin{abstract}
Acoustic Doppler current profilers are currently the main option for flow measurement and hydrodynamic monitoring of streams, replacing traditional methods. The spread of such equipment is mainly due to their operational advantages ranging from speed measurement to the greatest detail and amount of information generated about the hydrodynamics of hydrometric sections. As in the use of traditional methods and equipments, the use of acoustic Doppler profilers should be guided by the pursuit of data quality, since these are the basis for project and management of water resources constructions and systems. In this sense, the paper presents an analysis of measurement uncertainties of a hydrometric campaign held in Sapucaí River (Piranguinho-MG), using two different Doppler profilers - a Rio Grande ADCP $1200 \mathrm{kHz}$ and a Qmetrix Qliner. 10 measurements were performed with each equipment consecutively, following the literature quality protocols, and later, a Type A uncertainty analysis (statistical analysis of several independent observations of the input under the same conditions). The measurements of the ADCP and Qliner presented, respectively, standard uncertainties of $0.679 \%$ and $0.508 \%$ compared with the averages. These results are satisfactory and acceptable when compared to references in the literature, indicating that the use of Doppler profilers is valid for expansion and upgrade of streamflow measurement networks and generation of hydrological data.
\end{abstract}

Keywords: Streamflow measurement; Acoustic Doppler current profilers; Uncertainty analyses.

\footnotetext{
${ }^{1}$ Recebido em 26.03.2012 aceito para publicação em 07.05.2013.

${ }^{2}$ Doutor em Engenharia Mecânica (Transmissão e conversão de energia),Universidade Estadual Paulista Júlio de Mesquita Filho (UNESP), Faculdade de Engenharia de Guratinguetá (FEG), Brasil. E-mail: <mathidr@ yahoo.com.br>.

${ }^{3}$ Universidade Estadual Paulista Júlio de Mesquita Filho, UNESP, Brasil. E-mail: <perrella@ feg.unesp.br>.
} 


\section{INTRODUÇÃO}

O conhecimento das características de um ecossistema em sua condição natural é necessário para avaliar os efeitos da ação antrópica em bacias hidrográficas e permitir estabelecer comparações entre as condições hidrológicas e de qualidade da água em sistemas naturais e naqueles onde ocorre ação direta do homem (SANTOS et al., 2007). O uso de modelos computacionais para análise e simulação de processos hidrometeorológicos, sedimentológicos e ambientais em bacias hidrográficas tem aumentado de forma acelerada nas últimas décadas. Apesar das inúmeras possibilidades e funcionalidades oferecidas por esses modelos, o completo entendimento de sistemas naturais passa, inevitavelmente, pela sua observação e coleta de dados (SILBERSTEIN, 2006). Segundo Silberstein (2006), "a modelagem é um complemento importante à medição, mas não seu substituto; a ciência requer observação, sem a qual cessa o progresso no entendimento do meio ambiente, assim como seu apropriado gerenciamento".

Nesse sentido, os estudos e gerenciamento de bacias hidrográficas dependem da disponibilidade de dados hidrológicos com consistência, representatividade e resolução espaço temporal adequadas a cada tipo de aplicação. As possíveis entradas de água no sistema (bacia hidrográfica) incluem precipitação, orvalho, precipitação oculta e ascensão capilar, sendo as possíveis saídas a evapotranspiração, o escoamento superficial, o escoamento subsuperficial e o escoamento-base (CARDOSO et al., 2006). Dentre as variáveis hidrológicas mais representativas desse balanço hídrico, destaca-se a vazão fluvial (descarga líquida), seja em razão da maior facilidade de exploração da água superficial para diversos usos antrópicos, ou seja pela sua participação direta em diversos processos em bacias hidrográficas (erosão e inundações, por exemplo). Além da importância intrínseca da análise quantitativa de recursos hídricos, a maioria das análises qualitativas em bacias hidrográficas (estudos de parâmetros físico-químicos e de transporte de sedimentos) exige a correlação dessas variáveis com a descarga líquida nos pontos de interesse.

O uso de perfiladores acústicos Doppler de corrente (ADCPs) para medição de vazão em cursos d'água vem se difundindo em função das inúmeras vantagens que esses apresentam em relação aos métodos tradicionais, a exemplo do uso de molinetes hidrométricos mecânicos (MUELLER; WAGNER, 2009). Dentre essas vantagens, podem-se citar a maior rapidez de medição e cálculo da vazão e a grande quantidade de informações hidráulicas secundárias geradas (como dados geométricos da seção, perfis hidrodinâmicos, entre outros). O campo de aplicação dos ADCPs vem se expandindo, a partir do desenvolvimento de métodos para pósprocessamento e correlação de sinais com parâmetros físicos, com destaque para a estimativa da concentração de sedimentos em suspensão através da intensidade de retorno do sinal acústico (TESSIER et al., 2008; ELÇI et al., 2009).

Para medir a velocidade da água e, posteriormente, a vazão, os perfiladores acústicos Doppler utilizam-se da variação aparente que ocorre na frequência de uma onda quando há movimento relativo entre o emissor e o receptor (efeito Doppler) (RDI, 1996; SIMPSON, 2001). O equipamento mede, efetivamente, a velocidade de partículas suspensas no fluxo (sedimentos, plâncton etc.) que refletem parte das ondas emitidas. A geração dos perfis de velocidade ocorre através da divisão de cada vertical (ensemble) em várias células (bins ou cells) uniformes. O número de células de cada vertical depende da profundidade total e do tamanho de cada célula, fornecida pelo usuário. O perfilador realiza a amostragem de várias velocidades dentro de cada célula, sendo a respectiva vazão calculada a partir da média dessas velocidades. As células são definidas através de uma função triangular de ponderação, que compensa o fato de que a reflexão causada por partículas localizadas no centro de cada célula contribui com mais energia para cada portal receptor do que aquelas localizadas na extremidade da célula (RDI, 1996). Há também sobreposição entre células adjacentes causando correlação de aproximadamente $15 \%$ entre essas células.

Durante medições com ADCPs, alguns trechos da área molhada da seção hidrométrica não são efetivamente medidos, sendo eles: faixa superficial, faixa de fundo e margens. A faixa superficial é composta pelo somatório da profundidade de imersão dos transdutores com o blanking distance (distância ou tempo necessário para que os transdutores - que são simultaneamente emissores e receptores - parem de vibrar e recebam o sinal refletido). Próximo ao fundo ocorre o espalhamento do sinal, impedindo sua medição precisa. Nesses casos, as vazões parciais são calculadas através de extrapolações dos perfis obtidos nas áreas medidas.

Dada a importância dos dados hidrológicos para o gerenciamento e projetos envolvendo recursos hídricos, torna-se imperativo garantir a qualidade dos dados

Revista Árvore, Viçosa-MG, v.37, n.3, p.531-538, 2013 
brutos coletados em campo, uma vez que erros no processo de medição irão se propagar ao longo de sua utilização, ocasionando desde prejuízos econômicos até o comprometimento da segurança de empreendimentos.

Além da utilização de métodos e protocolos de medição, a análise de dados fluviométricos pós-coleta é fundamental para geração de informações confiáveis; nesse sentido, a análise de incerteza de medição pode constituir importante ferramenta. A incerteza de medição "é um parâmetro associado ao resultado de uma medição, que caracteriza a dispersão dos valores que podem ser razoavelmente atribuídos ao mensurando" (ABNT; INMETRO, 2003).

A incerteza de medição pode ser definida como um "parâmetro, associado ao resultado de uma medição, que caracteriza a dispersão dos valores que podem ser razoavelmente atribuídos ao mensurando" (ABNT; INMETRO, 2003), sendo indicador da qualidade e confiabilidade da medição. Ainda segundo ABNT e INMETRO (2003), quando a incerteza é expressa na forma de um desvio-padrão, atribui-se a ela a designação incerteza-padrão.

Lira (2002) classificou a incerteza-padrão em dois tipos, em função da sua forma de determinação:

-Tipo A: avaliada através de métodos estatísticos.

-Tipo B: avaliada através de outros métodos.

A análise de incerteza do tipo Aé aplicável “quando tenham sido feitas várias observações independentes para uma das grandezas de entrada sob as mesmas condições de medição" (INMETRO, 2007). Esse foi o método de análise empregado neste trabalho.

Já a análise do tipo B é realizada, segundo o INMETRO (2007), pelo julgamento científico baseado em todas as informações disponíveis sobre a possível variabilidade do mensurando por exemplo, dados de medições, especificações do fabricante, dados provenientes de calibração e de outros certificados etc.

Encontram-se na literatura diversas aplicações da análise de incerteza para avaliação da qualidade de dados hidrométricos, por exemplo, para a estimativa de parâmetros de curvas-chave (CLARKE, 1999), uso de molinetes hidrométricos mecânicos (WHALLEY et al., 2000), verificação de dados fluviométricos de regiões frias (SHIKLOMANOV, 2006), e ainda na análise de medições de velocidades com ADCPs a partir de barcos em movimento (KIM; YU, 2010).
Kim e Yu (2010) afirmaram que a análise de incerteza é fundamental para atestar a qualidade de medições realizadas com ADCP, sendo para isso utilizados métodos provenientes de outras áreas da ciência e da engenharia, originalmente voltados para outras aplicações, como aqueles propostos pela International Organization for Standardization (ISO, 1993), American Institute of Aeronautics and Astronautics (AIAA, 1995) e American Society of Mechanical Engineers (ASME, 1998). No Brasil, a Associação Brasileira de Normas Técnicas (ABNT), em parceria com o Instituto Nacional de Metrologia, Normalização e Qualidade Industrial (INMETRO), editaram uma versão em português do Guia de Expressão de Incerteza de Medição (ABNT; INMETRO, 2003) da ISO, sendo este a referência sobre o tema no país. Herschy (2009) citou o ISO/TS 25377:2007 Hydrometric Uncertainty Guidance HUG (ISO, 2007) como importante referência para análise de incerteza em aplicações hidrométricas, especificamente.

Diante do exposto, o presente trabalho apresenta uma análise de qualidade de dados de vazão obtidos com dois perfiladores acústicos distintos, através da análise de incerteza do Tipo A. Tais dados foram coletados sob as mesmas condições hidrodinâmicas, utilizando os mesmos protocolos de medição, o que permitiu comparar os resultados e inferir sua validade. A contribuição do trabalho reside no fato de os perfiladores Doppler ainda não serem utilizados massivamente no Brasil, ao contrário do que ocorre em diversos países do mundo - vide o caso, por exemplo, da Pesquisa Geológica dos Estados Unidos (USGS), que utiliza estes equipamentos de forma intensiva em suas redes hidrométricas - estando inclusive sujeito à resistência por parte de profissionais, instituições e empresas de hidrometria brasileiras. Muitos destes profissionais e instituições optam, comumente, pela utilização de medidores convencionais - principalmente molinetes hidrométricos mecânicos - atribuindo a estes a condição de referência. Cabe salientar que molinetes hidrométricos mecânicos, assim como qualquer instrumento de medição, estão sujeitos a diversas fontes de erro, seja por problemas no mecanismo, calibração ineficiente e, principalmente, erros de operação de natureza humana. A produção e divulgação de estudos atestando a qualidade de dados hidrométricos gerados por perfiladores Doppler podem contribuir significativamente para a expansão das redes hidrométricas nacionais e a maior disponibilização de

Revista Árvore, Viçosa-MG, v.37, n.3, p.531-538, 2013 
dados hidrológicos consistentes, fundamentais para o desenvolvimento das ciências hidrológicas e para o gerenciamento de recursos hídricos no Brasil.

\section{MATERIAL E MÉTODOS}

As medições foram realizadas no rio Sapucaí, em Piranguinho, MG. A seção fluviométrica (Figura 1), localizada nas coordenadas $22^{\circ} 23^{\prime} 46,56 " \mathrm{~S}$ e $45^{\circ} 31$ '45,32"W, apresentou profundidade média de 1,7 m, atingindo 2,7 $\mathrm{m}$ no seu talvegue, com largura molhada de $24,6 \mathrm{~m}$.

Foram utilizados dois perfiladores Doppler distintos: ADCP e Qliner. O ADCP é fabricado pela Teledyne RD Instruments, com tecnologia Broad Band, modelo Workhorse Rio Grande de $1.200 \mathrm{kHz}$. A precisão na medição das velocidades é de $\pm 0,25 \%$ da somatória das velocidades da água mais a do equipamento acrescidas de $\pm 0,25 \mathrm{~cm} \cdot \mathrm{s}^{-1}$, com resolução de $0,1 \mathrm{~cm} . \mathrm{s}^{-1}$ e velocidade máxima admissível de $\pm 20 \mathrm{~m} \cdot \mathrm{s}^{-1}$. As travessias foram realizadas com o auxílio de cabo (dada à pequena largura da seção), sem a utilização de motor. A configuração do equipamento e a coleta dos dados foram feitas pelo aplicativo Winriver versão 1.06, instalado em computador portátil acoplado via cabo ao ADCP.

O Qliner é um perfilador Doppler com frequência de $2.000 \mathrm{kHz}$ destinado a medições em pequenos cursos d'água, com profundidades máximas de $12 \mathrm{~m}$, fabricado pela empresa Qmetrix e atualmente distribuído pela OTT Hydrometry. A velocidade máxima de perfilamento é de $10 \mathrm{~m} \cdot \mathrm{s}^{-1}$, com precisão de $1 \% \pm 0,5 \mathrm{~cm} \cdot \mathrm{s}^{-1}$ (QMETRIX,
2005). Os dados são coletados através do aplicativo Qliner for Pocket PC, instalado em um palmtop, e posteriormente analisados em computador convencional, através do programa Qreview.

Foram efetuadas 10 medições consecutivas com cada um dos equipamentos, seguindo-se os procedimentos para garantia da qualidade estabelecida pelo Quality-Assurance Plan for Discharge Measurements Using Acoustic Doppler Current Profilers (OBERG et al., 2005) e pelo Procedimento-Padrão para Garantia de Qualidade das Medições de Descarga Líquida com Equipamentos Acústicos Doppler (GAMARO et al., 2008). A igualdade das condições de medição entre cada uma das 10 repetições foi confirmada através do monitoramento do nível d'água, por meio de régua linimétrica, tendo esse nível e, consequentemente, a vazão na seção, se mantido constantes. A Figura 2 apresenta os equipamentos utilizados e a visão geral da seção hidrométrica.

A Figura 3 ilustra os perfis de velocidade, as intensidades de retorno de sinal acústico e a trajetória do ADCP associada aos vetores de velocidades médias de uma das medições realizadas com o equipamento.

A Figura 4, análoga à Figura 3, ilustra os vetores velocidade e a geometria da seção obtida em uma das medições com o Qliner.

As vazões medidas com cada equipamento, resultando em 20 medições, foram submetidas a uma análise de incerteza-padrão tipo A. Segundo a ABNT
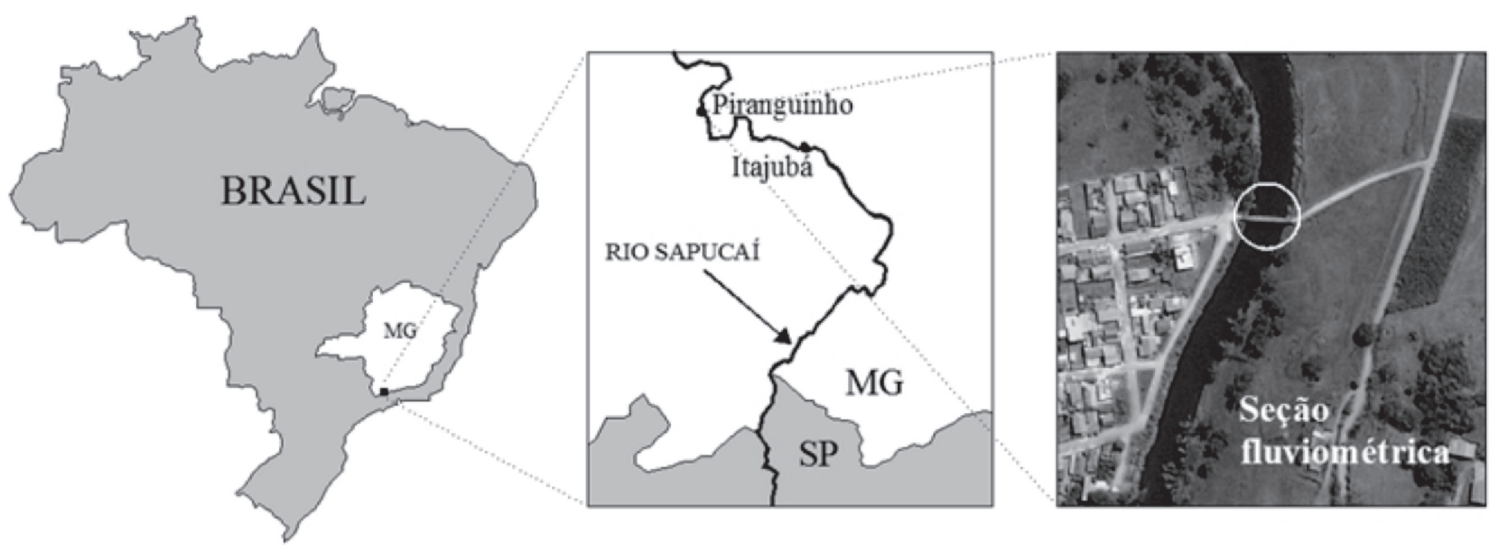

Figura 1 - Localização da área de estudo.

Figure 1-Study area localization.

Revista Árvore, Viçosa-MG, v.37, n.3, p.531-538, 2013 

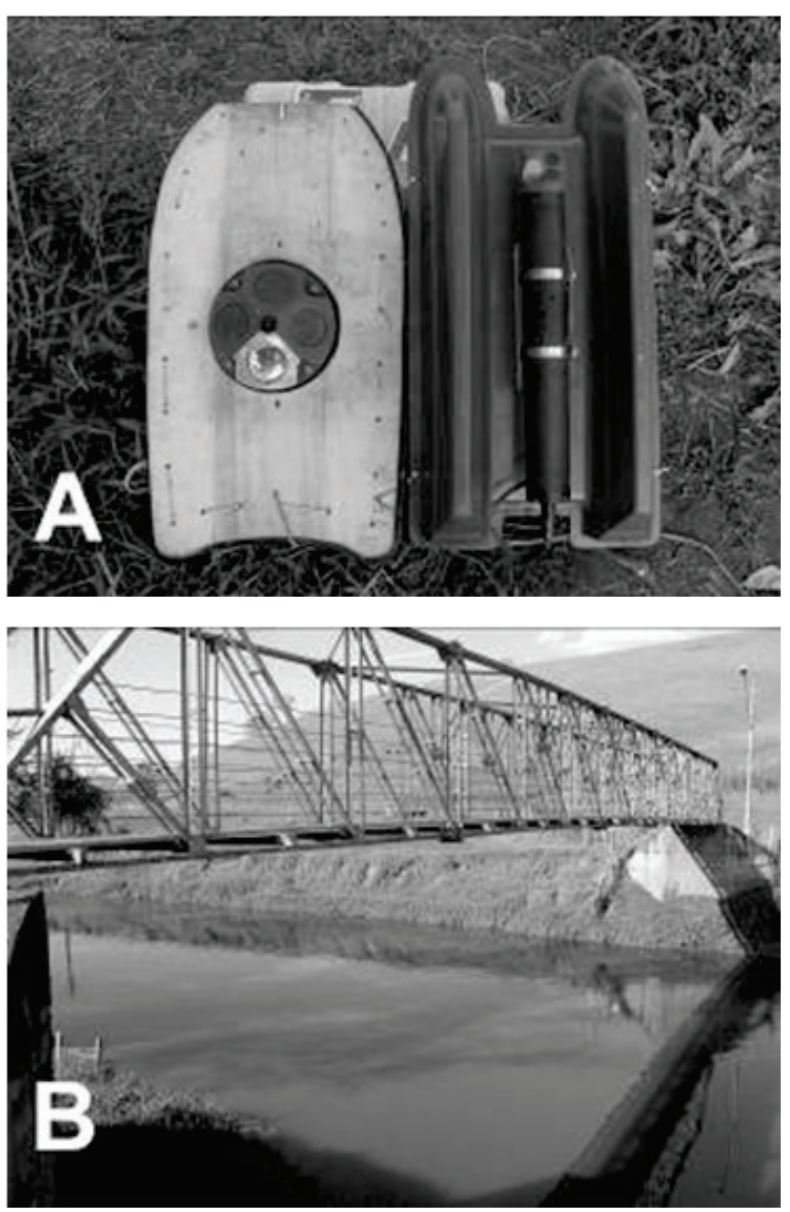

Figura 2 - ADCP (A, esquerda) e Qliner (A, direita) utilizados e seção hidrométrica (B) do estudo.

Figure $2-A D C P(A$, left) and Qliner $(A$, right) used and hydrometric section of the study.

e o INMETRO (2003), o cálculo se inicia pelas médias aritméticas dos dados (equação 1).

$$
\overline{\mathrm{q}}=\frac{1}{\mathrm{n}} \sum_{\mathrm{j}=1}^{\mathrm{n}} \mathrm{q}_{\mathrm{j}}
$$

sendo $\overline{\mathrm{q}}$ a vazão média $\left[\mathrm{m}^{3} \cdot \mathrm{s}^{-1}\right]$, n o número de medições da amostra e $\mathrm{q}_{\mathrm{j}}$ as vazões medidas $\left[\mathrm{m}^{3} \cdot \mathrm{s}^{-1}\right]$. Calculase, então, a variância experimental das amostras (equação 2).

$$
s^{2}(q)=\frac{1}{n-1} \sum_{j=1}^{n}\left(q_{j}-\bar{q}\right)^{2}
$$

sendo $\mathrm{s}^{2}(\mathrm{q})$ a variância experimental da amostra $\left[\mathrm{m}^{6} \cdot \mathrm{s}^{-2}\right]$.
A variância experimental é, então, dividida pelo número de medições, resultando na variância experimental da média (equação 3).

$$
s^{2}(\bar{q})=\frac{s^{2}(q)}{n}
$$

sendo $\mathrm{s}^{2}(\overline{\mathrm{q}})$ a variância experimental da média $\left[\mathrm{m}^{6} \cdot \mathrm{s}^{-2}\right]$. A raiz quadrada positiva da variância experimental da média corresponde ao desvio-padrão experimental da média que, por sua vez, é assumido como a incerteza padrão da medição (equação 4).

$$
\mathrm{s}(\overline{\mathrm{q}})=\sqrt{\mathrm{s}^{2}(\overline{\mathrm{q}})}=\mathrm{u}(\overline{\mathrm{q}})
$$

sendo s $(\overline{\mathrm{q}})$ o desvio-padrão experimental da média $\left[\mathrm{m}^{3} / \mathrm{s}\right]$ e u $(\overline{\mathrm{q}})$ a incerteza-padrão da medição $\left[\mathrm{m}^{3} / \mathrm{s}\right]$.

\section{RESULTADOS}

A Tabela 1 resume os resultados das medições realizadas e também dos cálculos da incerteza.

Os resultados da Tabela 1 indicam incertezas-padrão inferiores a $1 \%$ da média das medições realizadas com o ADCP e o Qliner. Além disso, a diferença entre essas médias é inferior a 3\%, evidenciando-se boa coerência entre os resultados de cada equipamento. Levando em consideração os intervalos de incerteza de cada equipamento, a diferença entre as médias encontradas varia de $1,8 \%$ a $4,1 \%$. Essa pequena diferença percentual em relação às médias, associada ao fato de as medições com cada equipamento terem sido realizadas de forma independente, indica que as médias encontradas se aproximam do valor real da variável medida (vazão).

\section{DISCUSSÃO}

Whalley et al. (2000) afirmaram que, em trabalhos com medidores de vazão tradicionais, erros em medições individuais da ordem de $\pm 10 \%$ são normalmente aceitáveis. No trabalho de De Doncker et al. (2008), vários métodos de medição de vazão são comparados, para determinação da influência de seções fluviais com vegetação na precisão dos métodos. Neste trabalho, incertezas de até $\pm 7 \%$ foram atribuídas a medições de vazão por métodos velocidade-área. Oberg e Mueller (2007), com base em diversas medições realizadas em experimentos laboratoriais e em cursos d'água naturais, afirmaram que incertezas de $\pm 5 \%$ devem ser esperadas em medições com ADCP com duração superior a 720 s. Herschy (2009), por

Revista Árvore, Viçosa-MG, v.37, n.3, p.531-538, 2013 

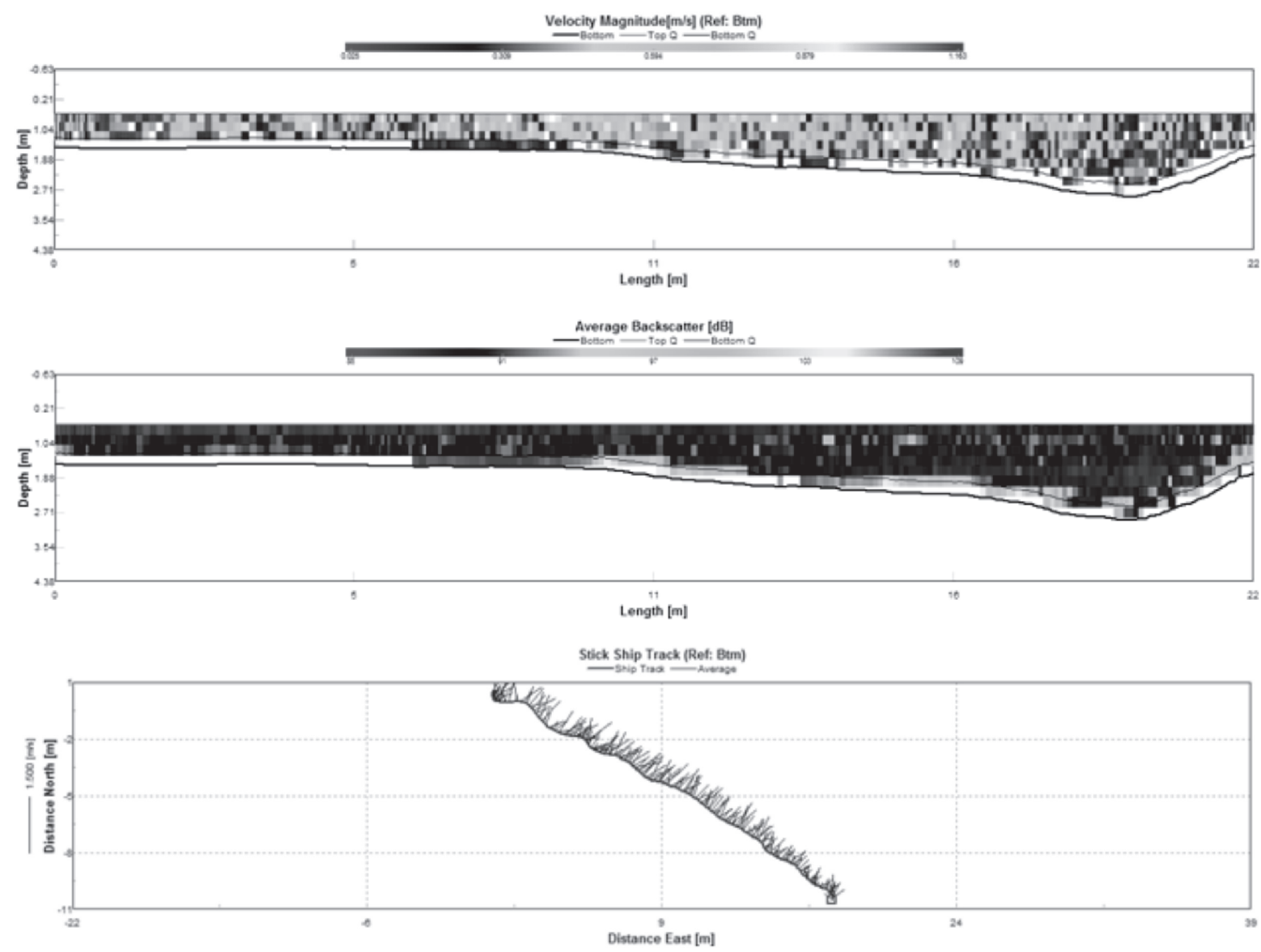

Figura 3 - Perfis de velocidade (acima), retorno acústico (centro) e trajetória (abaixo) do ADCP.

Figure 3 - ADCP velocity profiles (top), backscatter profile (center) and trajectory (down).
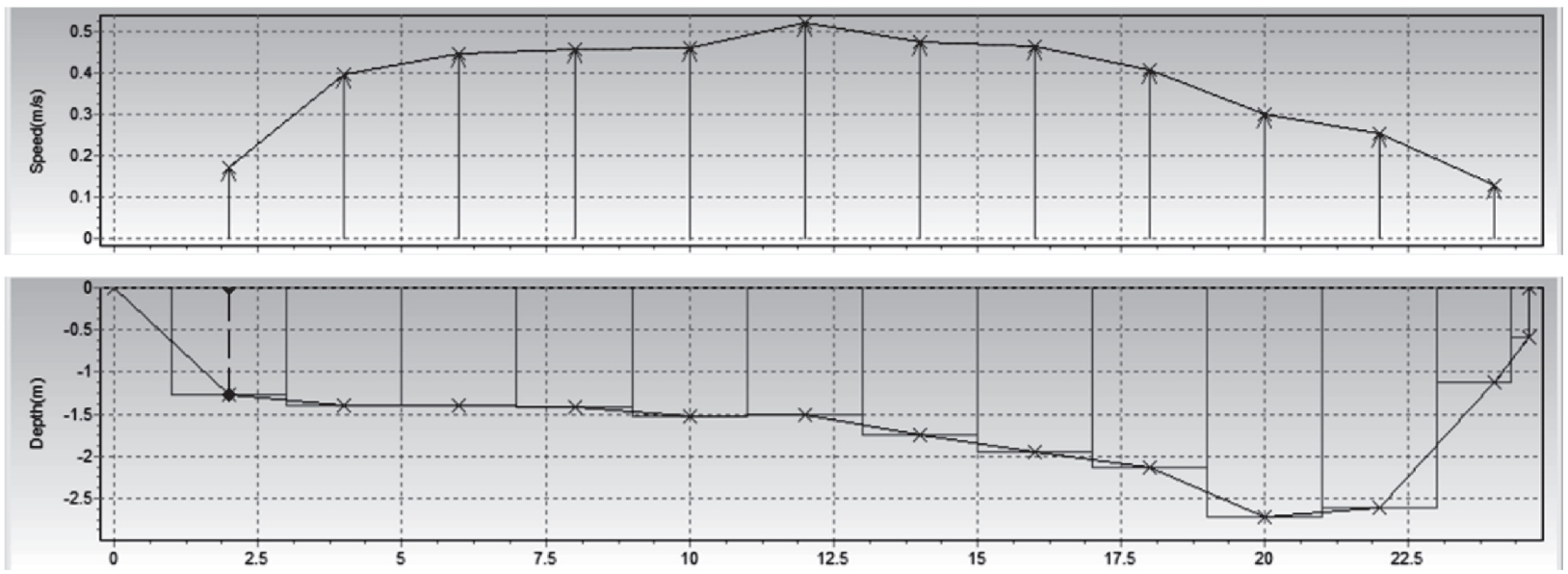

Figura 4 - Vetores velocidade (acima) e seção batimétrica (abaixo) do Qliner.

Figure 4-Qliner velocity vectors (top) and bathymetric section (down).

Revista Árvore, Viçosa-MG, v.37, n.3, p.531-538, 2013 
Tabela 1 - Resultados das medições e do cálculo das incertezas. Table 1 -Results of measurements and uncertainties calculation.

\begin{tabular}{lcc}
\hline Medição/Parâmetros & Vazão $\left[\mathrm{m}^{3} / \mathrm{s}\right]$ \\
\hline & Qliner & ADCP \\
1 & 16,113 & 16,043 \\
2 & 16,318 & 16,325 \\
3 & 15,733 & 16,178 \\
4 & 15,650 & 16,755 \\
5 & 16,143 & 16,778 \\
7 & 15,667 & 15,850 \\
8 & 15,848 & 16,574 \\
9 & 15,829 & 16,840 \\
10 & 16,293 & 16,166 \\
Média aritmética $\left[\mathrm{m}^{3} \cdot \mathrm{s}^{-1}\right]$ & 15,770 & 16,702 \\
Variância experimental $\left[\mathrm{m}^{6} \cdot \mathrm{s}^{-2}\right]$ & $\mathbf{1 5 , 9 3 6}$ & $\mathbf{1 6 , 4 2 1}$ \\
Variância experimental da média $\left[\mathrm{m}^{6} \cdot \mathrm{s}^{-2}\right]$ & $\mathbf{0 , 0 6 6}$ & $\mathbf{0 , 1 2 4}$ \\
Desvio-padrão experimental da média, incerteza-padrão $\left[\mathrm{m}^{3} \cdot \mathrm{s}^{-1}\right]$ & $\mathbf{0 , 0 0 7}$ & $\mathbf{0 , 0 1 2}$ \\
Incerteza-padrão $[\%$ da média] & $\mathbf{0 , 0 8 1}$ & $\mathbf{0 , 1 1 2}$ \\
\hline & $\mathbf{0 , 5 0 8}$ & $\mathbf{0 , 6 7 9}$ \\
\hline
\end{tabular}

sua vez, propôs que as incertezas na medição de vazão alcançáveis com ADCP, segundo os padrões ISO, são de até $\pm 5 \%$.

Devem-se considerar as diferentes condições operativas sob as quais são realizadas medições de vazão em rios com perfiladores acústicos: equipamentos instalados em barcos, nos quais pequenas variações na trajetória e nas verticais de medição são inevitáveis, seção fluvial com características nem sempre homogêneas, com possibilidade de existência de singularidades (pedras, galhos e outros) que afetem a medição da geometria do canal e, consequentemente, o cálculo da vazão, diferentes formas de processamento utilizado pelos variados modelos e marcas de perfiladores, dependência da experiência do operador e possíveis subjetividades durante a configuração dos equipamentos. Com base nessas condições e nas referências citadas, as médias e incertezas de medição obtidas no caso apresentado podem ser consideradas satisfatórias, indicando que os equipamentos e métodos utilizados são capazes de representar, com qualidade, as condições hidrodinâmicas da seção.

\section{CONCLUSÃO}

Os resultados deste estudo e sua comparação com referências na literatura indicam que os perfiladores acústicos Doppler produzem dados fluviométricos (vazões) de alta qualidade e confiabilidade que podem ser utilizados na geração de séries hidrológicas consistentes, necessárias em diversas áreas da engenharia e do gerenciamento de recursos hídricos.

\section{REFERÊNCIAS}

AMERICAN INSTITUTE OF AERONAUTICS AND ASTRONAUTICS -AIAA. Assessment of wind tunnel data uncertainty. New York: 1995.

AMERICAN SOCIETY OF MECHANICAL ENGINEERS -ASME.Test uncertainty: Instruments and apparatus. New York: 1998.

\section{ASSOCIAÇÃO BRASILEIRA DE NORMAS TÉCNICAS; INSTITUTO NACIONAL DE METROLOGIA, NORMALIZAÇÃO E} QUALIDADE INDUSTRIAL-ABNT;INMETRO. Guia para a expressão da incerteza de medição: terceira edição brasileira em língua portuguesa. Rio de Janeiro: 2003.

CARDOSO, C. A.et al.Caracterização hidroambiental da bacia hidrográfica do rio Debossan, Nova Friburgo, RJ. RevistaÁrvore, v.30, n.2, p.249-256, 2006.

CLARKE, R. T. Uncertainty in the estimation of mean annual flood due to rating-curve indefinition. Journal of Hydrology, v.222, p.185-190, 1999.

Revista Árvore, Viçosa-MG, v.37, n.3, p.531-538, 2013 
DE DONCKER, L.; TROCH, P.; VERHOEVEN, R. Accuracy of discharge measurements in a vegetated river.Flow Measurement and Instrumentation, v. 19, n.1, p.29-40, 2008.

ELÇI, S.; AYDIN, R.; WORK, P. A. Estimation of suspended sediment concentration in rivers using acoustic methods. Environmental Monitoring Assessment, v.159, p.255-265, dez. 2009.

GAMARO, P. E. M.; LISBOA, A. E.; QUIQUIO, D. Procedimento padrão para garantia de qualidade das medições de descarga liquida com equipamentos acústicos Doppler ADCP e ADP. Foz do Iguaçu: ABRH, 2008.

HERSCHY, R. W. Streamflow

measurement. 3.ed. New York: Taylor \& Francis, 2009.

INSTITUTO NACIONAL DE METROLOGIA, NORMALIZAÇÃO E QUALIDADE INDUSTRIAL -INMETRO. NIT-DICLA-021: Expressão da Incerteza de Medição. Rio de Janeiro: 2007.

INTERNATIONAL ORGANIZATION FOR STANDARDIZATION- ISO. Guide to the expression of uncertainty in measurement. Geneva: 1993.

\section{INTERNATIONAL ORGANIZATION FOR}

STANDARDIZATION - ISO. ISO/TS

25377:2007: hydrometric uncertainty guidance. Geneva: 2007.

KIM, D.; YU, K. Uncertainty estimation of the ADCP velocity measurements from the moving vessel method, (I) development of the framework. KSCE Journal of Civil Engineering, v. 14, n.5, p.797-801, 2010.

\section{LIRA, I.Evaluating the measurement} uncertainty: fundamentals and practical guidance.Londres: Institute of Physics Publishing, 2002.

MUELlER, D. S.; WAGNER, C. R. Measuring discharge with acoustic doppler current profilers from a moving boat. Reston: United States Geological Survey, 2009.

Revista Árvore, Viçosa-MG, v.37, n.3, p.531-538, 2013
OBERG, K. A.; MORLOCK, S.; CALDEWELL, W. S. Quality-assurance plan for discharge measurements using acoustic Doppler current profilers: scientific investigation report. Reston: United States Geological Survey, 2005.

OBERG, K. A.; MUELLER, D. S. Validation of streamflow measurements made with acoustic doppler current profilers. Journal of Hydraulic Engineering, v. 133, n.12, p.1421-1432, 2007.

QMETRIX. Qliner user manual.Hoofddorp: Qmetrix, 2005.

RD INSTRUMENTS.Acoustic Doppler Current Profiler: principles of operation a practical primer: Second edition for Broadband ADCPs.San Diego: 1996.

SANTOS, G. V.et al.Análise hidrológica e socioambiental da bacia hidrográfica do córrego Romão dos Reis, Viçosa-MG.Revista Árvore, v.31, n.5, p.931-940, 2007.

SHIKLOMANOV, A. I. et al.Cold region river discharge uncertainty - estimates from large Russian rivers.Journal of Hydrology, v.326, p.231-256, 2006.

SILBERSTEIN, R. P. Hydrological models are so good, do we still need data? Environmental Modelling\& Software, v.21, p.1340-1352, 2006.

SIMPSON, M. R. Discharge measurements using a broad-band acoustic Doppler current profiler: open-file report 01-1.Sacramento: United States Geological Survey, 2001.

TESSIER, C. et al. Estimation de la matiere en suspension a partir de l'intensiteretrodiffusee des courantometresacoustiquesaeffet Doppler (ADCP). ComptesRendus Geosciences, v.340, n.1, p.57-67, 2008.

WHALLEY, N.; IREDALE, R. S.; CLARE, A. F. Reliability and uncertainty in flow measurement techniques - some current thinking.Physics and Chemistry of the Earth, v.26, n.10, p.743-749, 2000. 